\title{
A quick measurement method for determining the incidence angle modifier of flat plate solar collectors using spectroradiometer
}

Article

Accepted Version

Creative Commons: Attribution-Noncommercial-No Derivative Works 4.0

Tian, Z., Deng, J., Zhang, S., Yao, R. and Shao, L. (2020) A quick measurement method for determining the incidence angle modifier of flat plate solar collectors using spectroradiometer. Solar Energy, 201. pp. 746-750. ISSN 0038-092X doi: https://doi.org/10.1016/j.solener.2020.03.059 Available at https://centaur.reading.ac.uk/89540/

It is advisable to refer to the publisher's version if you intend to cite from the work. See Guidance on citing.

To link to this article DOI: http://dx.doi.org/10.1016/j.solener.2020.03.059

Publisher: Elsevier

All outputs in CentAUR are protected by Intellectual Property Rights law, including copyright law. Copyright and IPR is retained by the creators or other copyright holders. Terms and conditions for use of this material are defined in the End User Agreement. 


\section{CentAUR}

Central Archive at the University of Reading

Reading's research outputs online 
1 A technical note (short communication) for Solar Energy

2

3 A quick measurement method for determining the incidence angle 4 modifier of flat plate solar collectors using spectroradiometer

6 Zhiyong Tian ${ }^{a}$, Jie Deng ${ }^{b}{ }^{*}$, Shicong Zhang ${ }^{c}$, Runming Yao ${ }^{b}$, Li Shao ${ }^{b}$

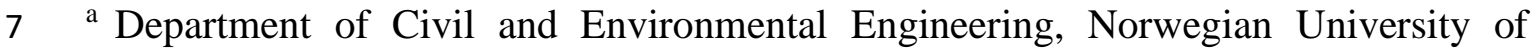

8 Science and Technology, Trondheim, Norway

$9{ }^{\mathrm{b}}$ School of The Built Environment, University of Reading, Whiteknights, Reading, 10 Berkshire, RG6 6DF, UK

$11{ }^{\mathrm{c}}$ China Academy of Building Research, Beijing 100013, China

* Corresponding author:

E-mail address: deng-jie2@163.com, j.deng@reading.ac.uk (J. Deng) 
A quick measurement method for determining the incidence angle modifier of flat plate solar collectors using spectroradiometer

\section{Abstract}

In real engineering of solar thermal applications, it needs considerable effort to determine the incidence angle modifier (IAM) of flat plate solar collectors, according to the test standards (BS EN ISO 9806, 2017; ASHRAE 93-2010, 2014). And the available method in the test standards is usually inapplicable to measure thermal performance of installed solar collectors with dust deposition effect in service. A quick measurement method is therefore presented to identify the IAM of flat plate solar collectors with less effort using a spectroradiometer. The quick method developed was validated with optical tests of a solar panel under the conditions of different incidence angles. It is inferred that the method not only helps to determine the IAM of flat plate solar collectors quickly without needing to run the collectors by energy power input, but also provides a pathway for assessing dust deposition effect on the thermal performance of installed flat plate solar collectors in service, as well as for determining the optical property attenuation of solar collectors in the long-term running.

Keywords: Flat plate solar collector; Incidence angle modifier (IAM); Spectroradiometer; Reflectance spectrum; Irradiance spectrum 


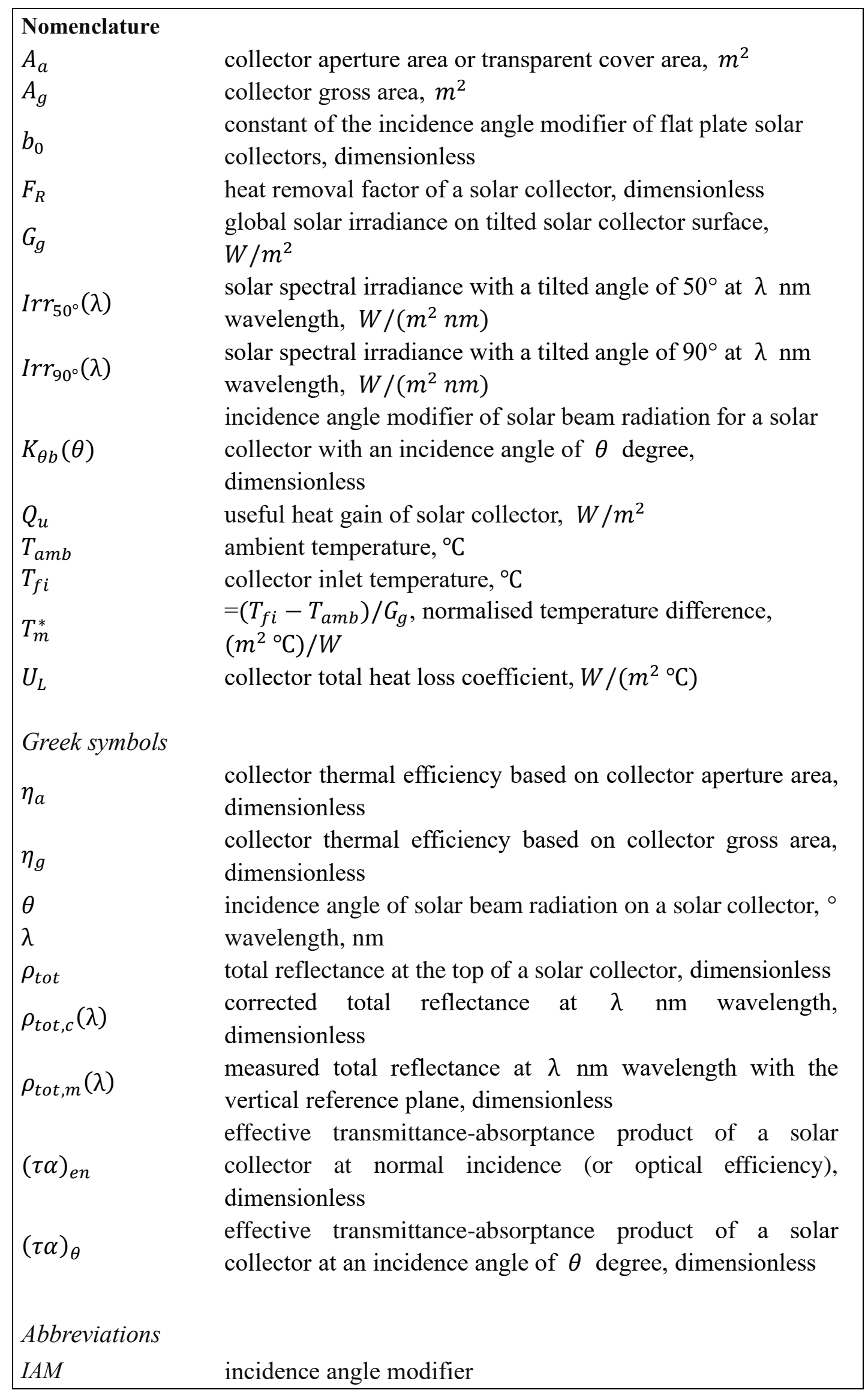




\section{Introduction}

Dynamic or transient thermal characteristics of flat plate solar collectors in naturally variable meteorological conditions are widely concerned in low-temperature solar thermal applications (Rojas et al., 2008; Deng et al., 2015a; Deng et al., 2016; Deng et al., 2017; Tian et al., 2018; Aleksiejuk et al., 2018). The incidence angle modifier (IAM) of the flat plate solar collectors plays an important role in the collector dynamic thermal performance due to diurnal motion of the sun. It is therefore indispensable to determine the collector IAM in assessing and predicting collector dynamic thermal performance in real engineering. Following the solar collector test standards (BS EN ISO 9806, 2017; ASHRAE 93-2010, 2014), however, it usually takes considerable efforts to obtain the IAM of flat plate solar collectors through thermal performance tests recommended. The collector thermal performance at fixed incidence angles (e.g. $0^{\circ}, 30^{\circ}, 45^{\circ}, 60^{\circ}$ ) is needed to test in order to get the IAMs. The solar collectors need to be run under specific incidence angle conditions over a period of time by power energy input and the test requirement is relatively rigorous in the steady-state. Particularly, determination of the IAM of solar collectors with variable geometries is more complicated because there are more than one direction of dependence for the IAM (Sallaberry et al., 2015; Hertel et al., 2015). The present study aims to introduce a quick measurement method for identifying the collector IAM using a spectroradiometer. The collector IAM can be obtained through executing a couple of quick optical test sequences without running the solar collectors by energy power input, meaning that less effort is taken to obtain the IAM compared to the thermal performance test method recommended in the 
73

existing test standards. More than that, the quick method is expected to assess dust deposition effect on the thermal performance of installed flat plate solar collectors in service on-site of solar fields, as well as to determine optical performance attenuation of the solar collectors in the long-term running in terms of optical tests. Table 1 gives a comparison between the available methods in the test standards and the presented method, which indicates the advantages of the latter.

Table 1. Comparison between the method available in the test standards and the presented method

\begin{tabular}{|c|c|c|}
\hline $\begin{array}{l}\text { Comparison of test } \\
\text { conditions }\end{array}$ & $\begin{array}{l}\text { Thermal performance test } \\
\text { method available in the } \\
\text { test standards }\end{array}$ & $\begin{array}{l}\text { The presented method } \\
\text { using spectroradiometer }\end{array}$ \\
\hline $\begin{array}{l}\text { Running solar thermal } \\
\text { collectors by power } \\
\text { energy input }\end{array}$ & Need & No need \\
\hline $\begin{array}{l}\text { Test conditions } \\
\text { incidence angles }\end{array}$ & $\begin{array}{l}\text { Fixed incidence angles } \\
\left.\text { (e.g. } 0^{\circ}, 30^{\circ}, 45^{\circ}, 60^{\circ}\right) \\
\text { which are restricted }\end{array}$ & $\begin{array}{l}\text { Flexible incidence angles } \\
\text { can be chosen as long as it } \\
\text { covers a wide range from } \\
0^{\circ} \text { to } 60^{\circ} \text {. }\end{array}$ \\
\hline Test duration & $\begin{array}{l}\text { Considerable efforts with } \\
\text { restricted conditions } \\
\text { (tends to cover several } \\
\text { sunny days) }\end{array}$ & $\begin{array}{l}\text { Less effort (usually can be } \\
\text { completed on one sunny } \\
\text { day) }\end{array}$ \\
\hline $\begin{array}{l}\text { Applicability in } \\
\text { determining optical } \\
\text { property of installed solar } \\
\text { collectors with surface } \\
\text { dust deposition }\end{array}$ & $\begin{array}{l}\text { Unable to determine dust } \\
\text { deposition effect without } \\
\text { intervention of normal } \\
\text { operating of the solar } \\
\text { collectors }\end{array}$ & $\begin{array}{l}\text { Applicable to determine } \\
\text { dust deposition effect and } \\
\text { optical property } \\
\text { attenuation of on-site solar } \\
\text { collectors }\end{array}$ \\
\hline
\end{tabular}

\section{Fundamentals of the measurement method}


2.1 Thermal performance test method available in the test standards for determining the collector IAM

Usually, the collector thermal efficiency $\left(\eta_{a}\right)$ based on collector aperture area $\left(A_{a}\right)$ is defined as (Duffie and Beckman, 2013):

$$
\eta_{a}=\frac{Q_{u}}{A_{a} G_{g}}=\frac{A_{g}}{A_{a}} \eta_{g}
$$

Concerning the collector thermal efficiency curve correlating $\eta_{g}$ (or $\eta_{a}$ ) with the normalised temperature difference $\left(T_{m}^{*}=\left(T_{f i}-T_{a m b}\right) / G_{g}\right)$, a simple linear model in equation (2) is commonly used to describe the collector steady-state thermal performance (Duffie and Beckman, 2013; BS EN ISO 9806, 2017; ASHRAE 93-2010, 2014).

$$
\eta_{g}=\frac{A_{a}}{A_{g}} \cdot\left[F_{R}(\tau \alpha)_{e n} \cdot K_{\theta b}(\theta)-F_{R} U_{L} \frac{\left(T_{f i}-T_{a m b}\right)}{G_{g}}\right]
$$

where $K_{\theta b}(\theta)$ - the collector IAM of solar beam radiation is described as (BS EN ISO 9806, 2017):

$$
K_{\theta b}(\theta)=1-b_{0} \cdot\left(\frac{1}{\cos \theta}-1\right)
$$

where $\theta$ is the incidence angle of solar beam radiation on the collector surface, ${ }^{\circ} ; b_{0}$ is a constant of the IAM of the flat plate solar collector, dimensionless.

In the solar collector test standards ( BS EN ISO 9806, 2017; ASHRAE 93-2010, 2014), 
the thermal performance test method is recommended in determining the collector IAM by testing the collector thermal efficiency at different incidence angles.

\subsection{Fundamental of determining the collector IAM using spectroradiometer}

Essentially, the optical efficiency $\left((\tau \alpha)_{\theta}\right)$ of the flat plate solar collectors can be separated from the collector thermal efficiency curve in Equation (2), as shown in Equation (4).

where the optical efficiency $(\tau \alpha)_{\theta}$ represents the transmittance-absorptance product of the collector at an incidence angle of $\theta$ (Duffie and Beckman, 2013).

The total reflectance $\left(\rho_{\text {tot }}\right)$ of the solar collectors is calculated in Equation (5), since the sum of the transmittance-absorptance product and the total reflectance equals one in terms of energy conservation. As the total reflectance $\left(\rho_{\text {tot }}\right)$ at the top of the collector surface in equation (5) can be measured directly using a spectrometer with a white reflectance standard, it is convenient to obtain the transmittance-absorptance products $\left((\tau \alpha)_{\theta}\right)$ of a flat plate solar collector at different incidence angles by measuring the total reflectance. Then the IAM is readily identified through linear fitting of $(\tau \alpha)_{\theta}$ versus the incidence angle $(\theta)$. It is reckoned as a quick measurement method to identify the collector IAM, since there is no need to run the collectors for thermal performance tests 
by energy power input and it can be completed on one sunny day.

$$
\rho_{\text {tot }}=1-(\tau \alpha)_{\theta}
$$

\section{Method validation with real tests and merit explanation}

\subsection{Test facilities and procedures of implementing the quick method}

A Black-Comet-SR concave grating miniature spectrometer (CXR-SR, StellarNet Inc., USA) was used to measure the total reflectance at the top of a flat plate solar panel at different incidence angles, in order to determine the constant $\left(b_{0}\right)$ of the IAM in Equation (4). The miniature spectrometer has a spectroradiometer mode by fitting the fiber-optic cable with a cosine receptor $\left(180^{\circ}\right.$ field of view), which allows measuring solar spectral irradiance in a range of wavelengths from 350 to $1000 \mathrm{~nm}$. The fiberoptic tip of the spectrometer with a white reflectance standard RS50 is shown in Figure 1(a). A solar panel with a tilted angle of $40^{\circ}$ shown in Figure 1(b) was used for optical tests under a clear sky. Manufacturing information of the panel was not available and disregarded, as the quick method did not require detailed information of the optical system and its components. There was a technical problem of directly measuring the total reflectance in Equation (5), because the white reference standard had to be tilted at the same angle as the solar panel $\left(40^{\circ}\right.$ in the case), while the fiber-optic tip pointing at the white reference standard would shade the reference standard on a sunny day. To avoid the technical problem, a vertical reference plane ( $90^{\circ}$ tilted angle) was taken in the tests of the total reflectance at different incidence angles. In the meanwhile, solar 
irradiance spectra at the tiled angles of $90^{\circ}, 50^{\circ}$ were recorded instantaneously with the

142 fiber-optic tip upwards fitted with the cosine receptor. Thus, the original total 143 reflectance measured based on the vertical reference plane can be corrected by 144 conversions of solar spectral irradiances, as given in Equation (6).

$$
\rho_{\text {tot }, c}(\lambda)=\rho_{t o t, m}(\lambda) \cdot \operatorname{Irr}_{50^{\circ}}(\lambda) / \operatorname{Irr}_{90^{\circ}}(\lambda)
$$

where $\rho_{\text {tot,c }}(\lambda)$ is the corrected total reflectance at $\lambda$ nm wavelength. $\rho_{\text {tot }, m}(\lambda)$ is with tilted angles of $50^{\circ}$ and $90^{\circ}$, respectively.

$$
\rho_{\text {tot }, \text { ave }}=\sum_{350}^{1000} \rho_{\text {tot }, m}(\lambda) \cdot \operatorname{Irr}_{50^{\circ}}(\lambda) / \sum_{350}^{1000} \operatorname{Irr}_{90^{\circ}}(\lambda)
$$

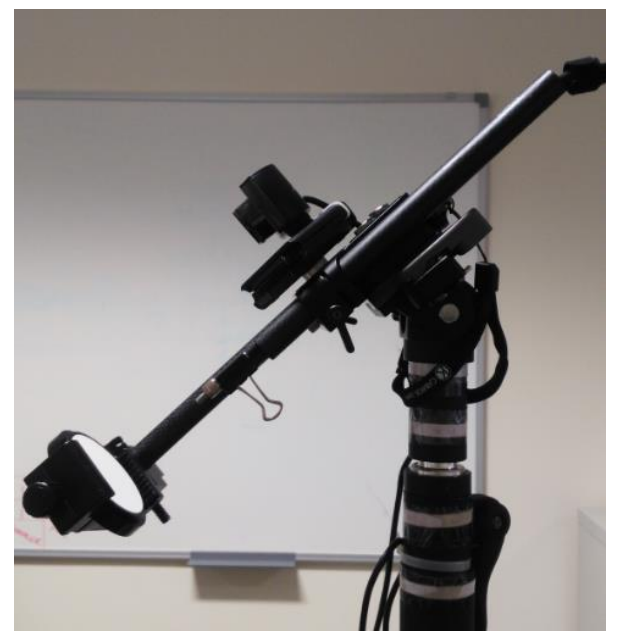

(a)

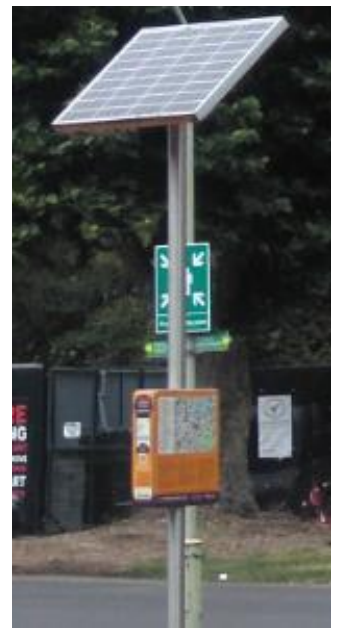

(b)

Figure 1 Testing facilities (a) fiber-optic tip of the spectrometer and reflectance standard 
RS50; (b) solar panel in test

A set of test sequences was executed with the solar panel at different incidence angles to determine the IAM. In a test condition of a specific incidence angle, the total reflectance spectrum of the solar panel with the vertical reference plane, solar spectral irradiance at both tilted angles of $50^{\circ}$ and $90^{\circ}$ were measured in a quick succession. A ruler was used to measure the shadow length of a fixed-length rod perpendicular to the surface of the panel, giving rise to the incidence angle which was the arctangent value of the quotient of rod shadow length divided by rod length.

\subsection{Reflectance spectra of the solar panel at different incidence angles}

Through a group of optical tests with the solar panel at different incidence angles, the measured total reflectance spectrum of the solar panel with the vertical reference plane, the measured solar spectral irradiance at tilted angles of $50^{\circ}$ and $90^{\circ}$ were obtained on a sunny day. Figure 2 shows the measured reflectance spectrum of the tested solar panel with fiber-optic tip pointing in the normal direction of the solar panel and to a vertical reference plane, while Figure 3 gives the corrected reflectance spectra at different incidence angles using equation (6), combining the measured solar spectral irradiance at tilted angles of $50^{\circ}$ and $90^{\circ}$. 


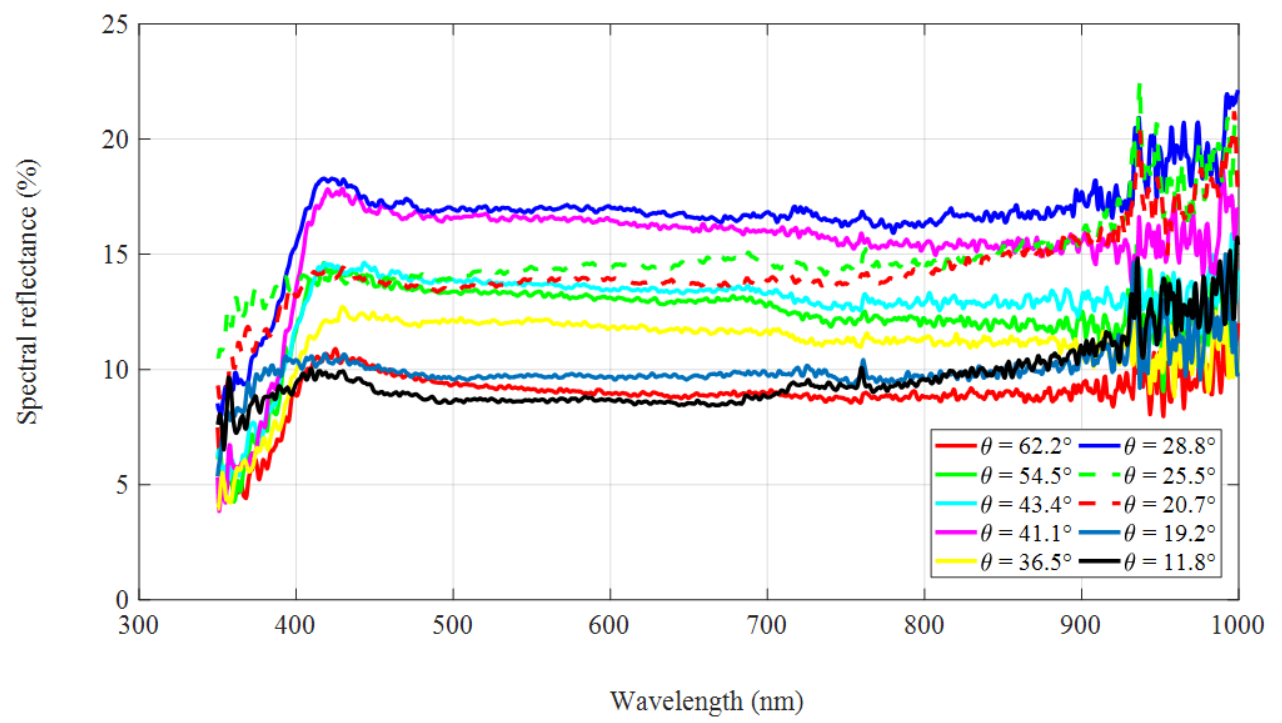

179 Figure 2 Measured reflectance spectrum of the tested solar panel with fiber-optic tip 180 pointing in the normal direction of the solar panel and to a vertical reference plane

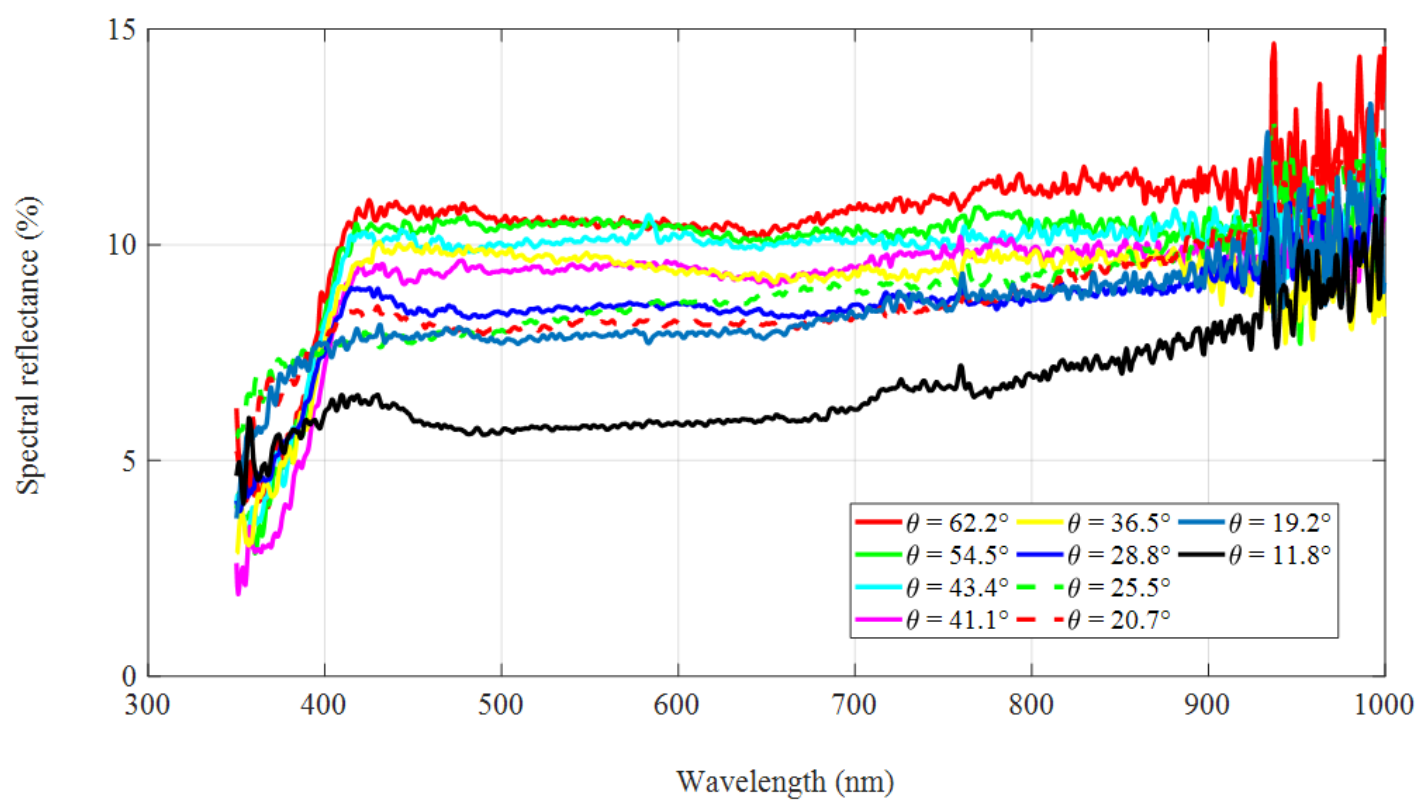

Figure 3 Corrected reflectance spectra at different incidence angles for the solar panel 
Based on the corrected reflectance spectra at different incidence angles for the solar panel (see Figure 3), the total reflectance at the top of the solar panel surface was calculated in equation (7). Then the transmittance-absorptance products $(\tau \alpha)_{\theta}$ at different incidence angles $(\theta)$ were obtained in equation (5). Figure 4 gives the linear fitting results of the transmittance-absorptance product $(\tau \alpha)_{\theta}$ versus $[1 / \cos \theta-1]$, in terms of the relations between each other described in equation (3). The coefficient of determination $\left(R^{2}\right)$ in the fitting was 0.852 , indicating a high correlation of $(\tau \alpha)_{\theta}$ collectors. 


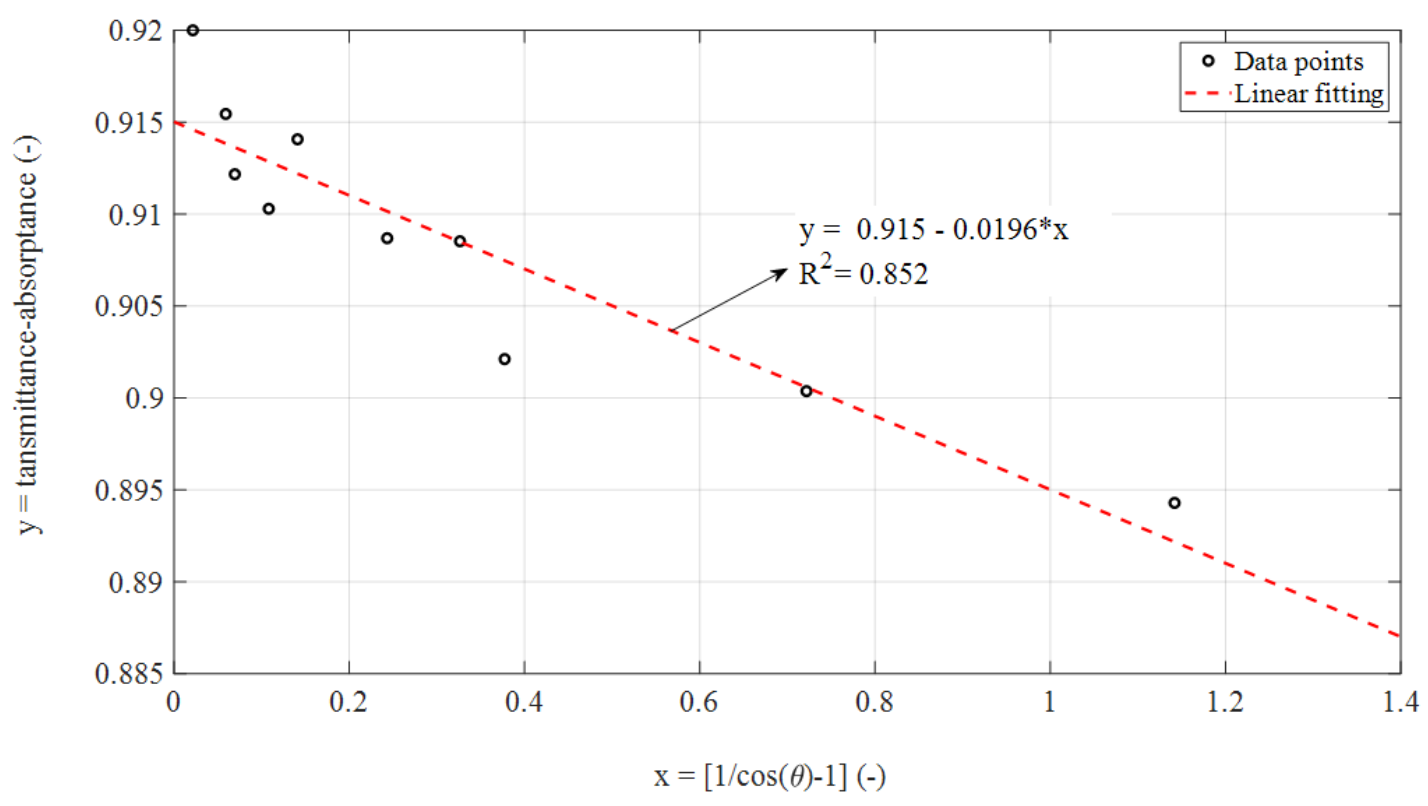

207

208

209

210

211

212

213

214

215

216

217

Figure 4 Linear fitting of transmittance-absorptance product $(\tau \alpha)_{\theta}$ versus $[1 / \cos \theta-$ 1] $\left(x=b_{0} \cdot(1 / \cos \theta-1), y=(\tau \alpha)_{\theta}\right)$

\subsection{Merits of the presented quick measurement method}

As the presented method decouples the IAM from measuring the collector thermal efficiency and directly applies tests of collector optical efficiency, it helps to save lots of effort comparing with the available method in the test standards (see Table 1). More than that, the method is applicable to determine the collector optical efficiency in some other scenarios in real engineering. Specifically, dust and ash in the air might be deposited on the installed flat plate solar collectors in service. The effect of dirt can degrade the transmittance of transparent covers of flat plate solar collectors to some extent (Garg, 1974). It was argued in Deng et al. (2015b) that the optical efficiency (effective transmittance-absorptance product) of a flat plate solar air collector was decreased by $8.39 \%$ when the transparent cover of the collector was under the condition 
of artificially severe dust deposition. Tanesab et al. (2019) presented the effect of dust with different morphologies on the performance degradation of various photovoltaic technologies. Nevertheless, the aforementioned methods used to quantify the dust deposition effect were limited to the case of installed solar collectors in service, as it was difficult to separate the solar collectors from operating systems. On this occasion, the quick measurement method provides a pathway for assessing the dust deposition effect on the collector thermal performance. The transmittance-absorptance products of the solar collectors in different degrees of cleanness can be obtained by quick optical tests. The dust deposition effect of the solar collectors can be assessed compared to the collector zero-loss optical efficiency $\left((\tau \alpha)_{e n}\right)$ with a clean surface.

On the other aspect, for the flat plate solar collectors serviced in solar thermal fields and exposed to sunlight in the long-term running, optical performance of the collector coating surfaces might be attenuated due to aging (Tian et al., 2019). It is difficult to quantify the thermal performance attenuation of the installed solar collectors without damaging the panels. The quick measurement method is expected to determine the collector optical property attenuation after a long period of running.

\section{Conclusion}

A quick measurement method using a spectroradiometer was presented to identify the incidence angle modifier (IAM) of flat plate solar collectors with less effort by using a spectroradiometer, compared to the thermal performance test method recommended in 
existing test standards. To testify the quick method, an installed solar photovoltaic panel was used to conduct optical tests under conditions of different incidence angles. The IAM coefficient of the flat solar panel was obtained with a relatively high $R^{2}$, confirming the applicability of the quick measurement method. Last but not the least, the method not only helps to determine the collector IAM quickly without needing to run the collectors by energy power input, but also provides a pathway for assessing the dust deposition effect and optical property attenuation of installed solar collectors in the long-term running.

\section{Declaration of interest: none.}

\section{Acknowledgment}

The third author Shicong Zhang wishes to thank the support from the National Key R\&D Program of China (Grant No. 2017YFC0702600).

\section{References}

Aleksiejuk, J., Chochowski, A., Reshetiuk, V., 2018. Analog model of dynamics of a flat-plate solar collector. Sol. Energy 160, 103-116. https://doi.org/10.1016/j.solener.2017.11.079 

Standard 93-2010 (R2014). ASHRAE Inc., Atlanta, USA.

Deng, J., Ma, R., Yuan, G., Chang, C., Yang, X., 2016. Dynamic thermal performance prediction model for the flat-plate solar collectors based on the two-node lumped heat capacitance method.

Sol.

Energy

135. https://doi.org/10.1016/j.solener.2016.06.060

Deng, J., Yang, X., Wang, P., 2017. Study on the second-order transfer function models for dynamic tests of flat-plate solar collectors Part II: Experimental validation. Sol. Energy 141, 334-346. https://doi.org/10.1016/j.solener.2015.01.045

Deng, J., Yang, X., Wang, P., 2015a. Study on the second-order transfer function models for dynamic tests of flat-plate solar collectors Part I: A proposed new model and a fitting methodology. Sol. Energy 114, 418-426. https://doi.org/10.1016/j.solener.2015.01.046

Deng, J., Yang, X., Yang, M., Wang, Z., 2015b. Experimental Study of a Single-pass Flat Plate Solar air Collector with Severe Dust Deposition on the Transparent Glass Cover. Energy $\quad$ Procedia $\quad 70, \quad 32-40$. https://doi.org/10.1016/j.egypro.2015.02.094

Duffie, J.A., Beckman, W.A., 2013. Solar Engineering of Thermal Processes: Fourth Edition, Solar Engineering of Thermal Processes: Fourth Edition. https://doi.org/10.1002/9781118671603

Garg, H.P., 1974. Effect of dirt on transparent covers in flat-plate solar energy collectors 15, 299-302. 
Hertel, J.D., Martinez-Moll, V., Pujol-Nadal, R., 2015. Estimation of the influence of different incidence angle modifier models on the biaxial factorization approach. Energy Convers.

Manag.

106 , 249-259. https://doi.org/10.1016/j.enconman.2015.08.082

Rojas, D., Beermann, J., Klein, S.A., Reindl, D.T., 2008. Thermal performance testing $\begin{array}{lllll}\text { of flat-plate } & \text { collectors. } & \text { Sol. } & \text { Energy } & \text { 746-757. }\end{array}$ https://doi.org/10.1016/j.solener.2008.02.001

Sallaberry, F., Pujol-Nadal, R., De Jalón, A.G., Martínez-Moll, V., 2015. Toward a standard testing methodology for solar thermal collectors with variable-geometry: The direct radiation incidence angle modifier issue. Sol. Energy 121, 31-40. https://doi.org/10.1016/j.solener.2015.05.029

Tanesab, J., Parlevliet, D., Whale, J., Urmee, T., 2019. The effect of dust with different morphologies on the performance degradation of photovoltaic modules. Sustain. Energy Technol. Assessments 31 , $347-354$. https://doi.org/10.1016/j.seta.2018.12.024

Tesfamichael, T., Wäckelgård, E., 2000. Angular solar absorptance and incident angle modifier of selective absorbers for solar thermal collectors. Sol. Energy 68, 335341. https://doi.org/10.1016/S0038-092X(00)00029-3

The British Standards Institution, 2018. BS EN ISO 9806: 2017 Solar energy. Solar thermal collectors. Test methods, British Standards. BSI Standards Limited 2018, London, UK.

Tian, Z., Perers, B., Furbo, S., Fan, J., 2018. Analysis and validation of a quasi-dynamic 

model for a solar collector field with flat plate collectors and parabolic trough collectors in series for district heating. Energy 142, 130-138. https://doi.org/10.1016/j.energy.2017.09.135

Tian, Z., Perers, B., Furbo, S., Fan, J., 2017. Annual measured and simulated thermal performance analysis of a hybrid solar district heating plant with flat plate collectors and parabolic trough collectors in series. Appl. Energy 205, 417-427. https://doi.org/10.1016/j.apenergy.2017.07.139

Tian, Z., Zhang, S., Deng, J., Fan, J., Huang, J., Kong, W., Perers, B., Furbo, S., 2019. Large-scale solar district heating plants in Danish smart thermal grid: Developments and recent trends. Energy Convers. Manag. 189, 67-80. https://doi.org/10.1016/j.enconman.2019.03.071

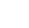

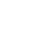

\section{Table Captions:}

Table 1. Comparison between the available method in the test standards and the presented method

\section{Figure Captions:}

Figure 1 Testing facilities (a) fiber-optic tip of the spectrometer and reflectance standard RS50; (b) solar panel in test 
330 Figure 2 Measured reflectance spectrum of the tested solar panel with fiber-optic tip 331 pointing in the normal direction of the solar panel and to a vertical reference plane

332 Figure 3 Corrected reflectance spectra at different incidence angles for the solar panel 333 tested

334 Figure 4 Linear fitting of transmittance-absorptance product $(\tau \alpha)_{\theta}$ versus $[1 / \cos \theta-$ $3351]\left(x=b_{0} \cdot(1 / \cos \theta-1), y=(\tau \alpha)_{\theta}\right)$ 